\title{
A elipse como estratégia narrativa nos seriados de TV
}

//I/I/I/I/II Carlos Gerbase ${ }^{1}$

1. Pós-doutor em Cinema pela Université Sorbonne Nouvelle - Paris 3 e doutor em Comunicação Social pela PUCRS. É professor titular no Curso de Produção Audiovisual e no Programa de Pós-Graduação em Comunicação da PUCRS. É cineasta, com sete longas lançados. É autor de quatro obras literárias de ficção e de três obras ensaísticas na área de cinema. E-mail: gerbase@terra.com.br. 
Resumo Este ensaio examina o uso de elipses ("buracos" temporais na trama) como uma das principais estratégias narrativas dos roteiristas de seriados de TV contemporâneos. Diversos exemplos são apresentados, de modo a caracterizar as elipses como um desafio cognitivo para o espectador, quebrando a linearidade e a excessiva redundância das séries mais antigas (antes de 1990), que subestimavam a inteligência do espectador.

Palavras-chave Televisão, seriados, elipse, narrativa, cinema.

Abstract This paper examines the use of ellipses ("holes" in the temporal plot) as a key narrative strategy of the writers of contemporary TV series. Several examples are presented in order to characterize the ellipse as a cognitive challenge to the public, breaking the linearity and excessive redundancy of the older series (prior to 1990) that would underestimate the intelligence of the viewer.

Keywords Television, TV series, ellipse, narrative, cinema. 
"É simples, nós vamos fazer filmes e passá-los na televisão, isso é tudo. Que a televisão vá para o inferno". (Jonh Huston, apud ROSS, 2005.)

A previsão de John Huston, feita em 1950, quando a televisão tinha pouco mais de dez anos, não se concretizou, pelo menos enquanto ele estava vivo. O cineasta morreu em 1987, ano em que a TV norte-americana exibia a nona temporada de Dallas com grande sucesso. Criado pelo roteirista David Jacobs, que nunca escreveu para cinema, e produzido pela CBS, o seriado é um típico produto televisivo. Embora utilize a mesma linguagem audiovisual dos filmes, Dallas tem convenções narrativas muito mais próximas das radionovelas dos anos 40 e 50 (é bom lembrar que a CBS, a NBC e a $\mathrm{ABC}$ nasceram como empresas radiofônicas) do que das obras de Huston e seus colegas cineastas.

Em 1990, contudo, os dois mundos começaram a se aproximar, graças à colaboração do cineasta David Lynch (dos longas Veludo azul e $O$ homem elefante) com o experiente roteirista de televisão Mark Frost (de Hill Street Blues). Twin Peaks quebrou muitas regras, apresentou muitas novidades estéticas e abriu caminho para uma nova maneira de fazer ficção na TV. Mesmo sendo uma história "estranha" para boa parte dos espectadores, Twin Peaks, escudada pela boa recepção da crítica, teve excelente audiência nos EUA e foi vendida para muitos países, inclusive o Brasil. De certo modo, David Lynch começou a fazer o que Huston previu. No entanto, a ficção televisiva contemporânea de qualidade, mesmo absorvendo estratégias narrativas cinematográficas, tem sua 
própria personalidade. O objetivo deste ensaio é refletir como esta personalidade foi construída.

\section{Ataque ao reino da redundância}

Entre as características dos bons seriados de TV contemporâneos, que rivalizam ou até superam em qualidade longas-metragens feitos para o cinema, está o uso de elipses narrativas, o que pressupõe a crença na inteligência do espectador. A TV tradicionalmente tratava o espectador como um ser que transitava entre a infantilidade e a absoluta precariedade mental. Adultos com três neurônios em funcionamento e acostumados com as tramas cinematográficas não suportavam o grau de redundância e obviedade das novelas, ou soap-operas, com seus enredos lineares eternamente repetidos em centenas de capítulos.

Adayr Tesche, ao estudar a ficção seriada tradicional na TV, explica que

\footnotetext{
O modo como a televisão manipula - tanto no sentido técnico de montagem, de elaboração do texto audiovisual, quanto no de operações de produção de sentido que não poderiam, evidentemente, estar imunes às variáveis ideológicas - está marcado pela reiteração, pelo esforço de legibilidade, plasticidade, auto-referencialidade e permeabilidade no tecido social. (TESCHE, 2006, p. 76)
}

O foco principal de Tesche é a telenovela, mas a grande maioria das séries e seriados pré-anos 1980 seguem, a nosso ver, as mesmas regras. O termo "legibilidade" é fundamental. O que é facilmente lido e compreendido deve ser perseguido; o que corre o risco de gerar um esforço grande de interpretação deve ser evitado. Tesche complementa:

É uma estruturação temporal regulada da ficção televisual que provê, efetivamente, o marco ordenado, sólido e seguro sobre o qual as fórmulas seriais desdobram o que dizem e, mais do que isso, mostram sua própria temporalidade e a oferecem à experiência do espectador.

(TESCHE, 2006, p. 83) 
Havia exceções para tal segurança narrativa? É claro, mas estas serviam apenas para confirmar a regra. Eis que, a partir de meados da década de 1980, num processo lento e gradual, o cenário foi mudando, primeiro nos Estados Unidos e na Europa, e depois no resto do mundo, graças ao surgimento de histórias seriadas mais curtas, normalmente divididas em temporadas. O número tradicional nos Estados Unidos é de 13 episódios por temporada, mas esta convenção foi se diluindo com o passar do tempo e a entrada de outros países no mercado.

Muitas das regras da seriação audiovisual que foram estabelecidas pelo cinema no começo do século vinte (com The Perils of Pauline, EUA, 1914; e Les Vampires, França, 1925), absorvidas pelas radionovelas (a partir de Painted dreams, EUA, 1930) e depois levadas para a TV (começando com Faraway Hill, EUA, 1946), ainda estão em vigor. Outras regras, contudo, foram criadas, e as antigas foram atualizadas. O gancho (cliffhanger), por exemplo, ainda é um recurso extensamente usado, mas hoje ele pode ser muito mais sofisticado e exigir maior capacidade interpretativa do espectador.

É importante tentar estabelecer, logo no início desta reflexão, a fronteira entre séries e seriados. Esses conceitos ainda estão em construção e podem originar mal entendidos. No âmbito desse ensaio, seriado é um produto audiovisual baseado em uma história longa, que é contada ao longo de vários episódios que se sucedem em ordem pré-estabelecida. É praticamente impossível acompanhar a narrativa se o espectador não estiver presente desde o primeiro episódio. Seria como entrar num filme de longa-metragem tradicional depois de meia-hora de projeção. Alguns exemplos de seriados bem sucedidos: Twin Peaks, Homeland, Breaking Bad, House of Cards, Mad Men e Downton Abbey.

Já uma série é constituída por pequenas histórias com começo, meio e fim, vividas por um grupo de personagens fixos, normalmente compartilhando um mesmo espaço de atuação (um edifício, uma cidade, um escritório). O espectador pode acompanhar qualquer episódio, em qualquer ordem, embora, é claro, o objetivo seja tornálo fiel à série como um todo. As séries também são divididas em temporadas. Alguns exemplos de séries bem sucedidas: Friends, Sex \& The City, Office e The Big-Bang Theory. Esses títulos de séries e seriados, pinçados entre centenas de obras lançadas, atendem a 
dois critérios: são, inegavelmente, bastante conhecidas, e foram integralmente assistidas pelo autor deste ensaio. A partir desse ponto, falaremos apenas de seriados.

\section{Elipses como estratégia narrativa e dramática}

A elipse é um "buraco" temporal na trama. Acompanhamos a ação até determinado momento e, no plano seguinte, nos deslocamos para o futuro. Esse "buraco" pode ter cinco minutos, uma hora, um dia, alguns meses, alguns anos, alguns séculos, ou até alguns milênios. Ao contrário de um flash-forward, que, como o próprio nome diz, nos proporciona uma breve antevisão (um flash) do futuro, após a qual voltamos para o presente narrativo, a elipse nos leva ao futuro e não permite um retorno tão rápido.

Regra geral, a história segue adiante, ficando o "buraco" para trás. Cabe ao espectador presumir o que aconteceu no tempo suprimido e fazer as relações necessárias entre o "antes" e o "depois" para que a elipse seja bem sucedida, tanto narrativa quanto dramaticamente. O cinema usa as elipses desde a sua invenção, mas elas se tornaram mais comuns e mais radicais a partir da década de 1940, que marca a mudança do cinema clássico para o cinema moderno. Aqui vão dois exemplos de elipses cinematográficas muito bem sucedidas.

Em 2001, Uma Odisséia no Espaço (2001, A Space Odyssey, 1968), de Stanley Kubrick, um animal que está, evolutivamente falando, entre um macaco e um hominídeo, usa um osso para bater em outros ossos, destruindo-os. Vamos supor que o animal que usa o osso como ferramenta seja um dos primeiros australopitecos, o que situa a sua ação há aproximadamente quatro milhões de anos, embora o filme não forneça qualquer data precisa. O ser joga o osso para cima e acompanhamos sua trajetória ascendente no céu azul, em câmera lenta. De repente, com a mágica instantaneidade do corte cinematográfico, vemos uma nave espacial em movimento sobre um fundo negro pontuado por estrelas.

Como o título indica, estamos em 2001. A elipse, portanto, cobre um período que inicia com a descoberta do uso de ferramentas pela linhagem do homo sapiens, até a representação de uma ferramenta que, no imaginário do final da década de 60 (o filme é de 1968), constituía o máximo de sofisticação tecnológica construída por 
essa mesma linhagem num futuro não muito distante. Bela elipse, que cumpre três funções. A primeira é narrativa, ao ligar eventos muito distantes no tempo, mas muito próximos conceitualmente. A segunda é dramática, permitindo uma identificação emocional do espectador com a espécie humana como um todo. E a terceira é estética, criando um momento de pura beleza fílmica, logo depois acentuado pelo uso da valsa Danúbio Azul, de Johann Strauss.

O segundo exemplo vem do filme Édipo rei (Edipo Re, 1967), de Pier Paolo Pasolini. Édipo já matou um desconhecido numa encruzilhada, já derrotou a esfinge, já foi empossado como rei de Tebas, já casou com Jocasta e está, neste momento, em sua noite de núpcias, indo para a cama com a rainha (que, é claro, não sabe ser sua mãe). Édipo e Jocasta se olham, com evidente desejo sexual, e deitam-se. Vemos a ação a uma certa distância, pudicamente, mas é óbvio para todos os espectadores o que está acontecendo: um ato, mesmo que, involuntário de incesto.

Sem qualquer transição, com a mesma instantaneidade que encontramos no exemplo anterior, vemos agora um cadáver em decomposição, representado com grande realismo. Esta elipse, embora seja muito menor na duração temporal, exige do espectador maior esforço interpretativo: a relação entre o sexo e a morte ficará mais evidente quando a trama original de Sófocles desdobrar-se nas próximas cenas. Com dados posteriores, principalmente a constatação de que Édipo e Jocasta têm quatro filhos, a mais velha uma préadolescente, é possível dizer que a elipse é de dez anos, ou perto disso.

Mais uma vez, podemos verificar a tríplice função da elipse. Na narrativa, liga o sexo incestuoso com a peste que assola a cidade de Tebas, embora nem o casal, nem a população, desconfiem disso. Enquanto ferramenta dramática, provoca uma radical mudança emocional no espectador, que "pula" de uma cena romântica de caráter sexual para uma cena de morte, tragédia e podridão. Esteticamente falando, é como se, num passeio no Louvre, passássemos imediatamente de um quadro de Rafael para um de Francis Bacon.

\section{Ganchos em seriados televisivos}

Quando falamos em seriados, não há como desconsiderar suas características próprias, que determinam sua identidade como obra 
audiovisual. A estrutura narrativa precisa ser analisada a partir das fragmentações normalmente apresentadas ao espectador, que geram pausas em pelo menos três diferentes níveis: entre os blocos de um mesmo episódio, divididos pelos intervalos comerciais na TV; entre os episódios de uma mesma temporada, normalmente separados por uma semana; e entre as temporadas, normalmente separadas por alguns meses.

Tudo isso cai por terra, é claro, se o espectador estiver com todos os episódios de todas as temporadas armazenados em seu computador e tiver, portanto, o poder de determinar seu próprio fluxo de consumo. Por outro lado, a obra em si continuará obedecendo às convenções criadas para o espectador mais "comum", que acompanha "ao vivo" na TV, ou que compra as temporadas quando estas são lançadas em DVD.

O que importa aqui é refletir como as elipses se relacionam com a fragmentação típica dos seriados. Antes de falarmos de elipses, contudo, somos obrigados a falar de ganchos. Na já citada The Perils of Pauline, surgiu uma das convenções mais tradicionais dos seriados: o perigo de morte de um personagem importante nos instantes finais do episódio.

A ação é suspensa no exato momento em que o espectador teme pela sorte do personagem, que, por exemplo, está amarrado aos trilhos de uma ferrovia e percebe uma grande locomotiva aproximando-se a toda velocidade. A solução narrativa (com o inevitável salvamento do personagem), acontece no começo do próximo episódio, e o espectador, nesse meio tempo, fica "enganchado" na história, aflito para saber como a peripécia será resolvida.

O teatro e a literatura também podem utilizar esse recurso, e Jonathan Culler, no âmbito da teoria literária, fala em "epistemofilia", ou o desejo de saber o final da história. Entretanto os seriados de TV criaram uma estrutura muito mais rígida, que virou ferramenta narrativa quase onipresente nos finais dos episódios. $\mathrm{O}$ "perigo de morte", é claro, pode ser substituído por alguma outra situação que gere grande suspense. O importante é deixar o espectador "enganchado".

\section{Ganchos e elipses}

A relação entre gancho e elipse não é muito simples. A princípio, numa cena de ação suspensa em seu momento de máxima tensão (o 
termo "suspense" vem exatamente deste procedimento narrativo de “suspender"), não há uma elipse, pois a história, no episódio seguinte, segue exatamente do ponto em que foi interrompida. A pausa é na fruição do espetáculo, e não na trama propriamente dita.

No entanto, em outros tipos de gancho, mais sofisticados, pode haver a intervenção de uma elipse. Vamos usar como exemplo o final do último episódio da terceira temporada do seriado inglês Downton Abbey. Um dos personagens principais, Matthew Crawley, que está extremamente feliz por ter se tornado pai, sofre um grave acidente automobilístico, e vemos seu corpo imóvel, estendido na estrada, o rosto sangrando, os olhos abertos. Está morto, sem sombra de dúvida.

Não é um gancho tradicional. A ação, pelo menos em relação ao personagem, foi apresentada de forma completa. Os ganchos para o espectador são os seguintes: (1) como os demais personagens, em especial sua esposa e sua mãe, vão reagir emocionalmente à tragédia?; e (2) que consequências a morte vai trazer para as relações econômicas e sociais da grande propriedade que dá nome à série? Como se trata do final de uma temporada, o gancho precisa ser poderoso, e a eliminação de um personagem principal cria ao mesmo tempo uma surpresa no presente (é uma peripécia imprevisível) e uma grande expectativa para o futuro, que, no entanto, só será oferecido no começo da próxima temporada, o que normalmente implica numa espera de alguns meses para o espectador.

No início da quarta temporada, o espectador, que provavelmente esperava a tradicional sucessão de cenas de reconhecimento da tragédia ("Seu marido morreu", "Seu filho morreu”, etc.), seguidas pela narrativa do enterro, é surpreendido com uma sequência relativamente desdramatizada envolvendo a família que habita Downton Abbey. As mulheres estão de luto, vestem preto, mas em poucos minutos fica evidente que o enterro aconteceu há algum tempo e a vida de todos, mesmo que marcadas pelo evento terrível, seguiu em frente.

O "buraco" cronológico entre o rosto do personagem, que acaba de morrer no fim da terceira temporada, e a primeira cena do primeiro episódio da temporada seguinte, em que a morte é comentada, mas não representada, é uma elipse criada pelos roteiristas, que habilmente complementa o efeito do gancho entre as temporadas. 
Numa trama novelesca televisiva tradicional, seria quase impensável ignorar as possibilidades dramáticas (e sensacionalistas) proporcionadas pela elaboração de cenas que representassem os diversos reconhecimentos da tragédia, seguidos pelo velório e pelo enterro. A elipse, assim, vai de encontro à expectativa do espectador e, de certo modo, contraria a convenção. Esta é uma das diferenças mais importantes dos seriados de TV contemporâneos: embora estejam sujeitos aos procedimentos usais, não estão escravizados por eles.

\section{Eliminando tempos mortos}

A elipse também pode ser definida como uma maneira de evitar tempos "mortos" e manter um bom ritmo na história. Se não há nada de importante acontecendo do ponto de vista narrativo, para que perder tempo contando? No caso da elipse relatada em Downton Abbey, o espectador é poupado de cenas desnecessárias (embora potencialmente dramáticas) e vai logo ao que interessa: o que a morte traz de novidades para a trama?

Em Homeland vamos encontrar uma elipse semelhante. Sabemos, no final da segunda temporada, que um dos personagens principais, Nicholas Brody, um ex-fuzileiro que pode ser (ou não) um terrorista perigoso, irá concorrer a uma vaga de deputado no Congresso norte-americano, apoiado pelo atual vice-presidente dos EUA. No começo da terceira temporada não há qualquer menção ao processo eleitoral. Brody já está em seu gabinete no Congresso, e a sua esposa faz grande esforço para apoiá-lo na vida pública. O espectador, que talvez estivesse esperando um relato das eleições, que eventualmente proporcionariam um gancho tradicional (será que Brody receberá o número de votos necessários?), é convidado a simplesmente imaginar o que aconteceu nos meses omitidos (o número de votos necessários foi obtido).

Uma elipse desse tipo, ao solicitar a imaginação criativa do espectador, faz com que ele se sinta “inteligente”, o que é uma estratégia eficaz para fidelizá-lo à trama. O perigo passa a ser uma eventual dificuldade do espectador para preencher o "buraco" temporal. Nesse caso, em vez de se sentir "inteligente" o espectador vai se sentir desorientado e pode se afastar da trama. É o mesmo medo que acompanha os roteiristas que gostam de usar muitos "flash-backs" e "flash-forwards" em seus enredos. Se 
o espectador não compreender a manipulação do tempo, pode retaliar desistindo do espetáculo.

Uma das formas de minimizar esse perigo nas elipses é explicitar o período do "buraco" temporal. No mesmo seriado, no último episódio da terceira temporada, assistimos à morte de Brody, sabemos que a personagem principal da trama (Carrie Mathison) está grávida dele e a gestação já tem cinco meses. Um letreiro com as palavras "Quatro meses depois" aparece para que o espectador compreenda, sem sombra de dúvida, que o momento do nascimento se aproxima. Um signo bem claro, a barriga pronunciada de Carrie, com certeza não foi considerado suficiente pelos roteiristas (ou pelos produtores). Em outras palavras: a elipse não poderia comprometer o gancho.

Num longa-metragem para cinema, não são raros os cartões que explicitam as elipses. Mas eles não são obrigatórios. As elipses citadas em 2001, Uma Odisséia no Espaço e Édipo Rei não utilizam esse recurso. De modo geral, o cinema tem o direito de ser mais misterioso e menos redundante que a TV.

\section{Adaptando os tempos narrativos aos intervalos de exibição}

Um fenômeno interessante, que surgiu na série I Love Lucy (EUA, 1951-1960), é a tentativa de adequar o universo diegético (ficcional) da trama com a vida "real" do elenco. Produzido durante nove anos, a trama incorporou a gravidez da atriz principal, Lucille Ball. Assim, o que seria um transtorno (esconder a barriga e o nascimento) acabou se transformando num trunfo.

Alguns seriados contemporâneos, especialmente os que atingem um número considerável de temporadas, também trabalham com essa relação entre o tempo ficcional e o real. Personagens podem, ao longo dos anos/temporadas, adquirir características inexistentes no começo, ou até sofrer transformações em seu caráter.

É evidente que a Peggy Olsen do começo do seriado Mad Men, uma secretária ingênua e indefesa, é muito diferente da Peggy da quinta temporada (cinco anos depois), uma publicitária de sucesso, independente, com ideias feministas.

Se essa estratégia for seguida, os intervalos entre as temporadas (quando assistidas na TV), normalmente de oito meses para seriados de 13 episódios, podem funcionar como elipses de oito 
meses na narrativa. É uma alternativa sempre sedutora para os roteiristas.

\section{Peripécias e elipses}

Aristóteles, em sua Poética (1991), ensina que "Os principais meios por que a tragédia move os ânimos também fazem parte do mito; refiro-me a peripécias e reconhecimentos". (p. 253). E, pouco depois, conceitua: "Peripécia é a mutação dos sucessos no contrário". (p. 258)

Caso reste alguma dúvida ao leitor, o exemplo dado é absolutamente claro: "Assim, no Édipo, o mensageiro que viera no propósito de tranquilizar o rei e de libertá-lo do terror que sentia nas suas relações com a mãe, descobrindo quem ele era, causou o efeito contrário." (ARISTÓTELES, 1991, p. 258)

Embora a narrativa tenha uma longa e rica história depois das tragédias gregas, o conceito continua válido. A "mutação de sucessos", isto é, a mudança brusca na expectativa do leitor/espectador em relação a determinado episódio, é uma das mais poderosas estratégias dos narradores contemporâneos, e pode ser facilmente verificada nos seriados de TV de qualidade.

É interessante notar que Aristóteles já considerava a peripécia (ao lado do reconhecimento) como um elemento capaz de separar uma ação "simples" de uma "complexa”:

Chamo ação "simples" aquela que, sendo una e coerente, (...), efetua a mutação de fortuna, sem peripécia ou reconhecimento; ação "complexa", denomino aquela em que a mudança se faz pelo reconhecimento ou pela peripécia, ou por ambos conjuntamente. (ARISTÓTELES, 1991, p. 258)

Manipulações do tempo narrativo (incluindo elipses) e um cuidadoso gerenciamento das informações disponíveis para cada personagem e para o espectador cumprem um papel muito importante na construção de peripécias. Vamos usar o exemplo de Aristóteles. Na tragédia de Sófocles, a ação propriamente dita é linear, dura um dia e acontece em frente ao palácio de Tebas, o que é considerado um ponto positivo por Aristóteles (há unidade de tempo e espaço). Parece não haver elipses. 
2. Se o período omitido contém informações, pode criar supressões na narrativa que configuram nossa atividade de formação de hipóteses. (Tradução nossa)
À medida em que a trama avança, contudo, percebemos que o passado vai se intrometendo no presente, com força cada vez maior, e essa intromissão não é linear. É fragmentada e cheia de elipses. É necessário notar que estas elipses podem adquirir diferentes contornos de acordo com a sua função narrativa:

(1) elipse objetiva ou "de tempo" - é um "buraco" temporal na narrativa acompanhada pelo espectador; essa elipse pode ser facilmente descrita na própria estrutura audiovisual (conforme fizemos nos exemplos de 2001, Uma Odisséia no Espaço e no Édipo Rei de Pasolini;

(2) elipse subjetiva ou "de conhecimento" - é uma lacuna importante no conhecimento de determinado personagem sobre a narrativa.

Em O roteiro de cinema, Michel Chion adota o termo "paralipse" como um caso particular de elipse, que já fora descrito em âmbito da teoria da literatura por Gérard Genette. Para Chion, a paralipse acontece "quando a narrativa é feita do ponto de vista de uma das personagens ou de um ponto de vista "onisciente", e algo de capital é escondido do público" (CHION, 1989, p. 218). Preferimos o termo "elipse de conhecimento", por ser auto-explicativo.

David Bordwell, em La narración em el cine de ficción, confirma essa relação entre os dois tipos de elipse: "Si el período omitido contiene información significativa, la elipsis puede crear una narración supresiva que configure nuestra actividad de formación de hipótesis”. (BORDWELL, 1996. p. 83)².

Uma elipse de tempo pode criar inúmeras elipses de conhecimento (e, em decorrência disso, a geração de hipóteses pelo espectador). A primeira elipse de conhecimento explícita em Édipo Rei é declarada quando Tirésias volta do oráculo, no começo da trama, e sustenta que a causa da peste na cidade é a ausência de punição para o assassino do rei Laio, que antecedeu Édipo no trono. Abra-se um "buraco" imenso na história - da morte de Laio ao presente (a peste), passando pela própria coroação de Édipo como soberano. 
Agenial arquitetura da trama de Sófocles, muitas vezes comparada à dos bons romances policiais, está baseada no preenchimento lógico e cronológico desta e de outras elipses. Édipo age como um detetive, procurando pistas para uma verdade que lhe será trágica, mas de que não pode escapar.

Para Laio e Jocasta, por exemplo, há uma grande elipse de conhecimento entre a entrega do filho de ambos, ainda um bebê, para um pastor, encarregado de abandoná-lo no monte Citéron para que morra, e o encontro trágico com um homem que vem do estrangeiro. Laio não o reconhece antes de ser assassinado na encruzilhada, mas acompanhamos cada um dos passos de Jocasta no rumo do reconhecimento de que Édipo, seu marido, é também seu filho.

Estas elipses de conhecimento acontecem graças a uma grande elipse de tempo planejada por Sófocles. Édipo Rei tem um ponto narrativo inicial cuidadosamente escolhido: a população exige que o rei faça alguma coisa em relação à peste que assola Tebas. Esse presente, rapidamente contaminado pelo passado, está separado por muitos anos do ponto inicial do mito: uma maldição proferida contra o jovem Laio, que seduz um adolescente quanto ainda era apenas o filho do rei Lábdaco.

Filmes e seriados contemporâneos, por sua natureza, não seguem o princípio da unidade de ação e de espaço, tão útil no teatro da Grécia clássica. Assim, as elipses contemporâneas citadas não são construídas pelos diálogos (que apontam para eventos pretéritos), e sim encenadas no presente narrativo. No Édipo Rei de Pasolini, o roteiro colocou em ordem cronológica o que, na peça, eram eventos recapitulados aos poucos, sem uma ordem rígida, a partir de um procedimento investigativo que vai juntando peças de um quebra-cabeça mitológico.

Há, em algumas tramas literárias e audiovisuais, um evidente jogo de "esconde-esconde" proposto ao leitor/espectador para obter determinados efeitos. É essencial, para o efeito trágico de Édipo Rei, que este vá descobrindo aos poucos quem é. Jocasta com certeza sabe antes, e o próprio leitor/espectador tem condições de anteceder-se ao personagem principal, sabendo ou não dos detalhes do mito que deu origem à peça. As elipses de conhecimento, sempre subjetivas, são a base do artesanato narrativo de Sófocles, rumo ao grande e catártico reconhecimento final. 
A elipse como estratégia narrativa nos seriados de TV | Carlos Gerbase

\section{Elipses na elaboração narrativa de Homeland}

Elipses de conhecimento, peripécias e reconhecimentos também são a base do seriado Homeland. E não é coincidência o fato de que há uma grande elipse de tempo na trama. Nicholas Brody, fuzileiro naval, casado, dois filhos, é enviado para o Iraque. Capturado pelo inimigo, fica um longo tempo preso, até ser libertado pelas tropas norte-americanas. De volta à pátria, é recebido como herói e torna-se um joguete político nas mãos do vice-presidente dos Estados Unidos.

Carrie Mathison, agente da CIA, acha que talvez ele não seja um herói de volta ao lar, e sim um terrorista recrutado para uma ação de grandes proporções em território americano depois de sofrer uma espécie de lavagem cerebral. Ela não tem certeza e precisa investigar, colocando microfones e câmeras na casa de Brody e seguindo todos os seus passos.

A elipse objetiva, de tempo (explicitada logo no início da trama) é de oito anos. Ela corresponde à elipse subjetiva de todos os personagens da trama, com a exceção, é claro, do próprio Nicholas Brody. Assim, o espectador passa a ser parceiro dos agentes da CIA (em especial de Carrie) em sua luta para desvendar o verdadeiro caráter do soldado que voltou ao lar, preenchendo o "buraco" temporal.

Mais uma vez, o ponto de partida da trama é cuidadosamente escolhido. Homeland não começa com a ida de Brody para o Iraque, nem com a sua prisão, e sim com a sua libertação. Poderíamos resumir assim os pontos de contato entre as peripécias das duas obras: 
Dossiê

\begin{tabular}{|c|c|c|}
\hline & ÉDIPO REI & HOMELAND \\
\hline $\begin{array}{l}\text { Brody, fuzileiro capturado no Ira- } \\
\text { que, é resgatado e vira heroi em } \\
\text { Washington }\end{array}$ & $\begin{array}{l}\text { Édipo, natural de Corinto, } \\
\text { derrota a esfinge, vira heroi e } \\
\text { rei de Tebas }\end{array}$ & Origem do personagem \\
\hline 0 terrorismo assola os EUA & A peste assola Tebas & Ambiente \\
\hline $\begin{array}{l}\text { Carrie diz que um prisioneiro foi } \\
\text { recrutado pelo terror }\end{array}$ & $\begin{array}{l}\text { Oráculo diz que Édipo não } \\
\text { resolveu o assassinato de Laio }\end{array}$ & $\begin{array}{l}\text { Ponto de ataque da } \\
\text { trama }\end{array}$ \\
\hline $\begin{array}{l}\text { Brody talvez não seja um verda- } \\
\text { deiro herói (e sim um terrorista) }\end{array}$ & $\begin{array}{l}\text { Édipo talvez não seja um } \\
\text { bom rei (e sim o causador da } \\
\text { peste) }\end{array}$ & $\begin{array}{l}\text { Consequência do ponto } \\
\text { de ataque }\end{array}$ \\
\hline $\begin{array}{l}\text { Entre a prisão de Brody e sua } \\
\text { libertação ( } 8 \text { anos) }\end{array}$ & $\begin{array}{l}\text { Entre o nascimento de Édipo } \\
\text { e sua coroação (por volta de } \\
20 \text { anos) }\end{array}$ & $\begin{array}{l}\text { Surge uma elipse de } \\
\text { tempo }\end{array}$ \\
\hline $\begin{array}{l}\text { Para a família de Brody (esposa, } \\
\text { filha e filho), para a CIA, para o } \\
\text { espectador }\end{array}$ & $\begin{array}{l}\text { Para o próprio Édipo, para } \\
\text { Jocasta, para Creonte e para o } \\
\text { espectador }\end{array}$ & $\begin{array}{l}\text { Surgem elipses de conhe- } \\
\text { cimento }\end{array}$ \\
\hline $\begin{array}{l}\text { Conduzida por Carrie Mathison (e } \\
\text { CIA) }\end{array}$ & Conduzida pelo próprio Édipo & Surge uma investigação \\
\hline $\begin{array}{l}\text { Carrie, CIA e o espectador recon- } \\
\text { hecem que Brody realmente } \\
\text { planejava uma ação terrorista de } \\
\text { grandes proporções }\end{array}$ & $\begin{array}{l}\text { Édipo, demais personagens e } \\
\text { o espectador reconhecem que } \\
\text { Édipo matou seu pai e casou } \\
\text { com sua mãe }\end{array}$ & Reconhecimentos \\
\hline $\begin{array}{l}\text { No final da terceira temporada, } \\
\text { morte }\end{array}$ & Automutilação e exílio & $\begin{array}{l}\text { Consequência para } 0 \\
\text { personagem }\end{array}$ \\
\hline
\end{tabular}

Há, no entanto, uma grande diferença nas conclusões das duas tramas. Édipo caminha inexoravelmente para sua própria destruição (ao saber o que realmente fez), enquanto o destino de Brody tem mais peripécias. Ao longo de 36 episódios, divididos em três temporadas, ele balança entre a confirmação de sua conversão ao terrorismo e uma possível reconversão aos seus ideais patrióticos. Acaba transformandose num clássico "agente-duplo", cuja fidelidade é sempre dúbia. 
De qualquer forma, é dentro da grande elipse temporal que nascem as múltiplas elipses de conhecimento. Cabe ao espectador preencher as lacunas ao lado dos investigadores e sofrer com eles nos momentos de reconhecimento.

O fato de Carrie e Brody se apaixonarem diminui a distância entre investigador e investigado. Cria-se uma espécie de Édipo duplo. Carrie tenta transformar o terrorista num agente "do bem", mas permanece sempre em dúvida sobre suas reais intenções. Brody prova que é um assassino a serviço dos EUA e morre no fim da terceira temporada em consequência de seu ato "heróico". Mas antes engravida Carrie e abre caminho para uma quarta temporada.

Finalmente, é necessário lembrar que Édipo Rei também tem sequência, nas peças Antígona e Édipo em Colono. A quarta temporada de Homeland talvez permita a continuação de nossa reflexão sobre as elipses.

\section{Considerações finais}

O desprezo de muitos teóricos e crítico de cinema pelas séries e seriados de televisão não têm mais qualquer razão de existir. É evidente que obras atualmente produzidas para a TV podem ser até melhores que muitos filmes. As razões desta súbita mudança no panorama estético do século 21 são muitas, e neste ensaio apontamos apenas uma, mas que julgamos essencial: o uso de elipses.

Num meio em que a redundância e a obviedade davam as cartas, a elipse surgiu como uma estratégia inovadora e capaz de atrair o espectador do cinema para a frente da TV (ou do "home-theater"). Ao usar "buracos" temporais e de conhecimento na história, os roteiristas de alguns seriados contemporâneos apelam para a inteligência e para a capacidade interpretativa do espectador. $\mathrm{O}$ que era simples pode ficar complexo, e o que era óbvio pode ficar mais difícil de entender.

Contrariando a linearidade das "soap-operas", certos seriados também usam as elipses para dar ritmo à edição e aproximar sua estética à dos bons filmes de longa-metragem. Com temáticas variadas e ritmo de produção em alta no mundo todo, esse novo paradigma está cada vez mais forte nos anos 2010 e pode, quem sabe num futuro bem próximo, desafiar o modelo de ficção hegemônico proposto por Hollywood desde a década de 1920 para a indústria audiovisual. 


\section{Referências}

ARISTÓTELES. Poética. São Paulo: Nova Cultural, 1991.

BERCIANO, Rosa Álvarez. La comedia enlatada: de Lucille Ball a Los Simpson. Barcelona: Gredisa, 1999.

BORDWELL, David. La narración em el cine de ficción. Barcelona: Paidós, 1996.

CARLOS, Cássio Starling. Em tempo real: Lost, 24 horas, Sex and the city e o impacto das novas séries de TV. São Paulo: Alameda, 2006.

CHION, Michel. O roteiro de cinema. São Paulo: Martins Fontes, 1989.

CULLER, Jonathan. Teoria Literária: uma introdução. São Paulo: Becca, 2001.

FURQUIM, Fernanda. Sitcom: definição e história. Porto Alegre: FCF Editora, 1999.

MATTOS, Sérgio. História da televisão brasileira: uma visão econômica, social e política. Petrópolis: Vozes, 2002.

PALLOTTINI, Renata. Dramaturgia de televisão. São Paulo: Moderna, 1998.

ROSS, Lillian. Filme. São Paulo: Companhia das Letras 2005.

SOUZA, José Carlos Aronchi. Gêneros e formatos na televisão brasileira. São Paulo: Summus Editorial, 2004.

TESCHE, Adayr. Gênero e regime escópico na ficção seriada televisual. In: DUARTE, Elizabeth B. \& DE CASTRO, Maria L.D. Televisão: entre o mercado e a academia. Porto Alegre: Sulina, 2006

THOMPSOM, Robert. Television's second golden age: from 
Hill Street Blues to ER. New York: Continuum, 1996

WOLTON, Dominique. Elogio do grande público: uma teoria crítica da televisão. São Paulo: Ática, 1996

Filmografia (ordem cronológica de produção)

Édipo Rei (Edipo Re), Itália, 1967. Direção: Pier Paolo Paolini. 2001, Uma Odisséia no Espaço (2001, A Space Odyssey), EUA, 1969. Direção: Stanley Kubrick.

O homem elefante (The Elephant Man), EUA, 1980. Direção: David Lynch.

Veludo azul (Blue Velvet), EUA, 1986. Direção: David Lynch.

Séries e seriados (em ordem cronológica de produção)

The Perils of Pauline, EUA, 1914. Criação: George Seitz e Charles Goddard.

Les Vampires, França, 1925. Criação: Louis Feuillade.

Painted Dreams, EUA, 1930-1943. Criação: Irna Phillips.

Faraway Hill, EUA, 1946. Criação: David Lewis. 
I love Lucy, EUA, 1951-1960. Criação: Lucille Ball e Desi Arnaz.

Dallas, EUA, 1978-1991. Criação: David Jacobs.

Hill Street Blues, EUA, 1981-1987. Criação: Michael Kozoll e Steven Bochco.

Twin Peaks, EUA, 1990-1991. Criação: David Lynch e Mark Frost.

Friends, EUA, 1994-2004. Criação: David Crane e Marta Kauffman.

Sex E The City, EUA, 1998-2004. Criação: Darren Star.

The Office, Inglaterra, 2001. Criação: Rick Gervais e Stephen Merchant.

Mad Men, EUA, 2007-2014. Criação: Matthew Weiner.

The Big-Bang Theory, EUA, 2007-2013. Criação: Chuck Lorre e Bill Prady.

Breaking Bad, EUA, 2008-2013. Criação: Vince Gilligan.

Downton Abbey, Inglaterra, 2010-2014. Criação: Jullian Fellowes.

Homeland, EUA, 2012-2014. Criação? Howard Gordon e Alex Gansa.

House of ards, EUA, 2013-2014. Criação: Beau Willimon. 